\title{
Traditional Practices on Mother and Child Health Care in Rajbanshi Community of Nepal
}

\author{
Nawa Raj Subba \\ Department of Psychology, Tribhuvan University, Kathmandu, Nepal
}

Email address:

dr.subba2015@gmail.com

To cite this article:

Nawa Raj Subba. Traditional Practices on Mother and Child Health Care in Rajbanshi Community of Nepal. American Journal of Health Research. Vol. 3, No. 5, 2015, pp. 310-317. doi: 10.11648/j.ajhr.20150305.18

\begin{abstract}
This is a qualitative study on traditional health care of mother and child in Rajbanshi community in Nepal. The aim of the study was to explore traditional maternal and child health care and to uncover harmful practices. Methods in this descriptive study employed in - depth interviews and FGDs with traditional birth attendants, traditional healers, female community health volunteers, health workers and mothers. Tools were semi - structured questionnaire and checklists. The study sample included 60 from Morang, Jhapa, and Sunsari districts. Of them, 30 were from traditional healers, traditional birth attendants (TBA), and female community health volunteers (FCHV) and health workers another 30 were mothers included for three FGDs conducted in 2013. Findings show Rajbanshi culture has native care of mother and child health. Guru Gosai, Gosai, Ojha, and Dhami are traditional healers in the community. Guru Gosaiis also essential to conduct birth, marriage and death rituals. The traditional causes of diseases are deities, witchcrafts, evil spirits, a touch of pithiya/chhatka, and poor sanitation. Traditional healers find the cause through a jokhana. They treat patients by chanting a mantra, jharphuk, jadibuti, buti, and ferani. TBAs and health workers conduct home delivery however trend of hospital delivery increased. The study figured out a mark of a stigma where women pithiya or chhatka are suspected as cause of disease and illness in others. Community people perceive them unholy and unfriendly. Thus, pithiy $a$ and chhatka women face unfair treatment. They are vulnerable to maternal and child health. On the other, the traditional practice of cutting the umbilical cord by a barber during a delivery and shaving off newborn's head after a delivery by the barber are harmful practices.
\end{abstract}

Keywords: Traditional Practice, Maternal Child Care, Stigma, Harmful Practices, Rajbanshi Nepal

\section{Introduction}

A variety of traditional care systems and practices such as Ayurveda, Tibetan medicine, family care, and faith healing exist in Nepal. Modern medicine Allopathy been introduced in the seventeenth century but became dominant from the middle of the 20th century [1]. However, alternative medical systems are still popular at the community level. The exit of this variation reflects a tolerant co - existence and co operation between differing forms of therapeutic practices in communities [2] [3] [4] [5].

Nepal is a country having high maternal mortality rate 229/100, 000[6] and high child mortality 54/1000 in the region [7]. In Nepal, public health infrastructure equipped with central, regional, zonal and district level 86 hospitals, 205 primary health care centers, 822 health post, and 2987 sub - health posts. Registered Female community health volunteers (FCHV) in number 48897 and non - registered traditional birth attendants (TBA) are working at community level across the country [8]. In addition, traditional healers are present almost in each cluster.

Modern medicine takes up health and illness from bio medical viewpoint. On the contrary, traditional care has a native concepts, images, values and perception of the world [9]. It is more complex to understand within a single cultural frame. Community has multiple perspectives within a particular society with dualism and parallelism. Dualism is a situation where a sector of society developed 'westernized' and the other sector remain 'traditional' [10]. Within a particular culture, these two sectors have interactions and operate parallel to each other. Furthermore, the existence of cultural diversity could produce the different types of explanations and interpretations within a particular society [11].

White explained different attributions of causes determined by the cultural patterns. Interpreting these disorders is crucial in choosing the healing approach [12]. Such different explanation is now accepted when one looks 
at definition of health defined by WHO as a state of physical, mental, social, spiritual well - being not merely absent disease and infirmity. In Nepal, we need to retrospect the cultural varieties and illness in explaining health through ethnic cultures. It is important to look at how particular ethnic groups perceive disease and illness. The present study is based on the perspective of Rajbanshi cultural group.

\section{Rationale of Study}

To comprehend a traditional practice of maternal and child health care, one should familiar with the indigenous psychological standpoint of that particular cultural group. Kim and Berry defined Indigenous psychological study is the scientific study of human behavior or mind that is native, that is not transported from other regions, and designed for its people [10]. It generally advocates examining knowledge, skill and belief people have about them and such aspects studied in their natural contexts. Based on this, theories, concepts, and methods developed to correspond with psychological phenomena.

Human behavior is complex in itself. People know things by own knowledge. Everyone looks at a new thing with their own perspective. Berger and Luckmann illustrated socially constructed reality is belief to develop in three stages: externalization, objectivation, and internalization [13]. The stage at which people builds a piece of social and cultural knowledge is called externalization. Objectivation is that attained by men becomes independent object. Man transforms objective knowledge to subjective conscious is internalization. Through the ordinary process of socialization, children acquire knowledge without personally going through externalization and objectivation. So succeeding generations taught a particular fact and it becomes further entrenched into the cultural reality.

This study attempted to study Rajbanshi people and their mother and child health behavior in its natural context to answer the questions in the research problem. Here is an examination to look at the general facts and meaning attached to health practices in different cultural groups. Traditional health care practices of the mother and child during pregnancy and birth delivery has its own cultural meaning, logic, and significance. The practice of visiting modern health care is also rising. Traditional and modern coexistence of dual health care practices has both advantages and disadvantages in health seeking behavior and treatment. In such conditions it is natural to become curious to know what economic, social, educational, age level of Rajbanshi practice traditional and modern health care and what is the reason for continuing traditional health care practices or using modern health care practices? What are traditional causes of diseases or illnesses? How a traditional healer finds out the cause of disease? How does a traditional healer treat a mother or child? Do they have any traditional precautionary measures? What are harmful practices? What changes been taken places in their health seeking behavior in mother and child health care? The present study attempted to answer the questions as rose above.

The culture of rearing and caring of mother and child in Rajbanshi is not only the wealth of the country it is worthwhile for humankind. Knowledge, belief, and practice make them a cultural group among different ethnic groups. By indigenous perspective, this study has explored the knowledge and practice and identified harmful practices as well. The researcher comprehends and interprets knowledge, beliefs and practices taking into account the indigenous psychology and the social construction theories. This study has fulfilled the gap in the academic literature about traditional maternal and childcare practices among Rajbanshi of Nepal.

\section{Review of Literature}

Globally traditional health care practice is also an integral part cultural life. In the culture of Dominican Republic, traditional healers and family members are influential advisers on first health - seeking behaviors and self - care practices. A study of in that country has described over physical, mental and spiritual properties of illness. Family members influenced women for first care seeking to indigenous healers. When indigenous treatments are unsuccessful, the women sought care from trained health workers [14]. In Vietnam health care seeking behavior was found being influenced by the cultural perception of illness. Vietnamese tradition explains ill - health and disability are due to the supernatural and spiritual realm. Many people, therefore, use traditional methods of healing or in combined with Western medicine. Buddhism has a great influence on the traditional thinking and practice of Vietnamese people [15].

Early marriage and early pregnancy are socio - cultural as well as public health problem globally. That is still present among indigenous and underdeveloped communities. The multiplicity and complexity of social, cultural factors, and the government policy created the environment where a young pregnant dies during childbirth. A study on health find out risks associated with a use of the traditional healers and midwives, some other cultural factors contribute to poor genitourinary health among Zimbabwean women [16].

In Pakistan, maternal and child health was improved by raising the socio - economic status through development activities and non - formal education. It showed a positive effect on health seeking behavior, morbidity, mortality and overall empowerment of women [17]. By and large economic condition and education are determinants in causing maternal and child deaths. The situation in Rajasthan India also showed that economic condition played a determinant role in causing death and care - seeking behavior in a study [18]. The study revealed the family perception about treatment. Treatment cost was a barrier which was unaffordable to them and $60 \%$ had to borrow who sought health care. Next barrier was distance of health facility. Study highlighted a major technical cause of death was inadequate number of skilled health care provider present in hospitals. A study conducted in Uttar Pradesh India [19] investigated the knowledge, attitudes, and behavior of both men and women to enhance the status of 
reproductive health of couples. Results indicated that women are not free to seek for health care as per need in UP India.

Self - medication is a common practice when minor ailments occur. In Nepal, a study conducted in Gorkha district described the health - seeking practice. When villagers fall ill he can consult any of local healers. His first step is to present his problem to family and friends in the hope that some simple advice and a few words of sympathy is enough to make him feel better. Alternatively, he may head for the tea shops where he may buy a bottle of Ayurvedic medicine brought up from Kathmandu [20]. In another district of Nepal in Nuwakot uncovered local conceptions about an illness. The study indicated that illnesses related with multiple links of meta physical universe. People need to have an astrological calculation for the treatment in reference to a person and the planets. So, a disease is a misalignment between one's self and planets spell misfortune as grahabigriyo. Any adverse effects of planets on a person may cause illness [21].

\section{Conceptual Framework}

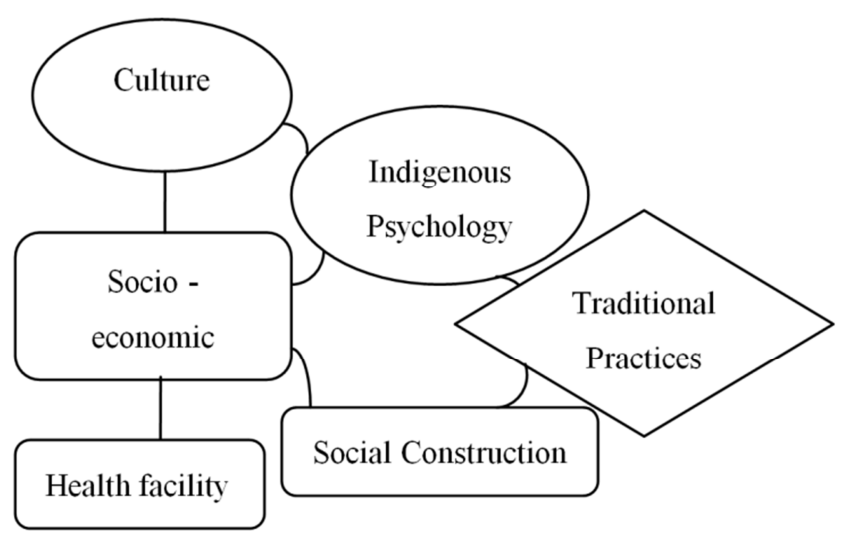

Figure 1. Development of traditional practices.

The conceptual framework comprises of variables such as culture, socio - economic condition, health facility, indigenous psychology, social construction and traditional practices. A culture guides people's indigenous psychology to form the traditional practices. The native knowledge or an indigenous psychology on health care practices is interdependent with the socio - economic condition and available health services in the community. Rajbanshi mothers perceive things with their existing knowledge that is externalization of practices. The community institutionalizes the traditional practices that are objectivation. Numbers of external factors interact with the particular ideas, feeling, and experience of the community. The community may continue or transform practices during the course of internalization of maternal and child health care. The study used the perspectives of indigenous psychological theory [10] and social construction theory [13] to comprehend traditional practices among Rajbanshi community.

\section{Objective of the Study}

The objective of the study was to probe into traditional practices of maternal and child health care and to detect harmful practices among Rajbanshi community in Nepal. Specific objectives were to identify traditional beliefs on disease, its cause and treatment. The study also aims to uncover the role of traditional healers and practices during pregnancy, delivery and post delivery with neonatal care.

\section{Methods and Materials}

\subsection{Research Design}

This is a cross - sectional and descriptive study, which explores qualitative data. Alasuutari described qualitative research consists of qualitative materials, specimens; they are a piece of the world being studied [22]. In the case of qualitative research, it is particularly important to set the phenomenon concerned in a broader context. Therefore, the research design has made up of able with proper methods and tools to collect qualitative data.

\subsection{Study Setting and Sampling}

The clusters chose by purposive sampling to ensure traditional practice and rural from Morang, Jhapa and Sunsari districts presuming traditional practices are common in rural clusters. A roster of naming head of households, traditional healers, TBAS, FCHVs and health workers made. Respondents were selected from the roster by random sampling technique to interview and hold meetings. In - depth interviews with traditional healers 10, with TBAs/FCHVs 10, and with health workers 10 conducted and 3 FGDs with 30 mothers also organized in three districts.

\subsection{Data Collection Tools and Procedure}

Semi - structured questionnaire and checklist used in in depth interviews and FGDs. Respondents were well informed about the study and its purposes. They assured the information would not be disclosed individually and findings used for the benefit of Rajbanshi community. In - depth interviews conducted individually at their home and FGD conducted at common places. The questionnaire comprised open - ended questions. Interviews also recorded with tape recorder after taking permission. The filled up questionnaire and check lists later checked up by replaying the recorder to complete points.

\subsection{Data Analysis}

The analysis of data started with the thorough reading of the questionnaires. Meaning units or themes corresponding to the objectives identified and sorted. Common as well as different views are all incorporated in the analysis chart. They grouped according to the theme and raised issues during discussion and interviews. Similar ideas merged and dissimilar ideas remained in the analysis. The compiled data again grouped and summarized according to the objectives. Findings presented in table and boxes. 


\subsection{Ethical Consideration}

Tribhuvan university institute of humanities and social sciences research committee gave the permission for the study. The researcher visited government authorities' three district development committees and three district public health offices to tell about the study and took verbal consent. The researcher also visited local development committees and Rajbanshiwelfare organizations and leaders to tell about the aim of the study and sought for co - operation. The interviewer took verbal consent from each respondent during interviews and meetings.

\section{Findings}

\subsection{Characteristics of Respondents}

Table 1 shows the characteristics of the respondents: traditional healers, TBAs, FCHVs, health workers involved by sex, districts as well as their work experience in year.

Table 1. Respondents.

\begin{tabular}{|c|c|c|c|}
\hline Traditional Healers & Sex & Districts & Working Years \\
\hline TH1 & Male & Morang & 25 \\
\hline TH2 & Male & Morang & 30 \\
\hline TH3 & Male & Morang & 20 \\
\hline TH4 & Male & Morang & 32 \\
\hline TH5 & Male & Morang & 32 \\
\hline TH6 & Male & Morang & 25 \\
\hline TH7 & Male & Jhapa & 20 \\
\hline TH8 & Male & Jhapa & 20 \\
\hline TH9 & Male & Jhapa & 21 \\
\hline TH10 & Male & Sunsari & 19 \\
\hline \multicolumn{4}{|c|}{ Traditional Birth Attendants } \\
\hline TBA1 & Female & Morang & 22 \\
\hline TBA2 & Female & Morang & 25 \\
\hline TBA3 & Female & Morang & 17 \\
\hline TBA4 & Female & Jhapa & 19 \\
\hline TBA5 & Female & Morang & 26 \\
\hline \multicolumn{4}{|c|}{ Female Community Health Volunteers } \\
\hline CHV1 & Female & Morang & 20 \\
\hline FCHV2 & Female & Morang & 20 \\
\hline FCHV3 & Female & Morang & 25 \\
\hline FCHV4 & Female & Jhapa & 21 \\
\hline FCHV5 & Female & Sunsari & 22 \\
\hline \multicolumn{4}{|l|}{ Health Workers } \\
\hline ANM1 & Female & Morang & 21 \\
\hline ANM2 & Female & Morang & 16 \\
\hline ANM3 & Female & Morang & 14 \\
\hline ANM4 & Female & Jhapa & 18 \\
\hline ANM5 & Female & Sunsari & 20 \\
\hline HA6 & Male & Morang & 28 \\
\hline HA7 & Male & Morang & 27 \\
\hline AHW8 & Male & Morang & 21 \\
\hline AHW9 & Male & Sunsari & 20 \\
\hline AHW10 & Male & Jhapa & 29 \\
\hline
\end{tabular}

\subsection{Traditional Healers}

Guru Gosai, Gosai and Dhami or Ojha are traditional healers. They are keys of traditional health care practices. Guru Gosai is senior to Gosai and Dhami or Ojha. Guru Gosai performs all rituals from birth to death. Gosai, Dhami or Ojha do only health care practices. Each traditional healers has certain catchment area that covers around $20-25$ households.

Traditional healers have their own meaning of causes of illness and diseases. They have a diagnostic procedure called jokhana by which they determine cause and treatment. Apart from health care Guru Gosai and Gosai are vital in all rituals from birth, marriage to death. They are a part of the culture. They are not only traditional healers. Hence in spite of modern health care intervention traditional practices are deeply rooted in the culture in Rajbanshi community. A traditional healer described the cause of illness and diagnosis:

The cause of illness in mother and child is the anger of deities called 'ghardeota', 'sadguruthakur', 'hanuman thakur', 'matabrahmahini'. Another reason of illness is touching children by 'pithiya' or 'chhatka'. If a 'pithiya' woman touches a healthy child, it can cause malnutrition and other illnesses. 'Jokhana' is a diagnosis procedure to find out the cause of illness. The pointed direction of 'Tulasi' leaf displaying on the water pot manifests diagnosis 'Jokhana'. TH1

They treat mainly by worshiping deities, jharphuk, buti, jadibuti and offering things and promises. Another traditional healer described treatment procedure:

I treat my patients by 'jharphuk' and 'phukphak' by chanting mantras. Usually, I give her or him 'buti' to wear over the neck or upper arm. Sometimes I give a 'jadibuti' medicine. I make 'buti' from plants leaves, stem, roots, and other materials. I put and cover these medicines into nail sized small copper box and jammed with wax. I give them to wear on the full moon day (purnima) or new moon day (aushi). While doing a 'jharphuk', I do ferani or 'bhakal'to the deity by offering pigeons, guava, milk, 'sindoor', rice, sweets or goods.TH5

\subsection{Traditional Maternal Care During Pregnancy}

Rajbanshi calls a pregnant woman as dorjuwa which means a woman having two bodies. Traditional birth attendants (TBA) are caretaker during pregnancy and delivery. In their language, they called sudeni or dhaiaamaa. She looks after a woman during pregnancy and delivery. A pregnant woman cannot go to the temple, to go to another's house, and places where death ritual or bad events take place. Pregnant women are also not allowed to look or hear bad things. They need to take more food but not lift heavy things.

They take the precaution for the safe delivery of a pregnant woman who has lost a baby before or had a stillbirth. They take a treatment from a traditional healer.

A woman having a history of stillbirth when gets pregnant need treatment called 'aalibadhn'e for the safety of upcoming delivery. For this I give her a 'buti' to wear over the neck or upper arm on full moon day (purnima), or on new moon day (aushi). TH2

\subsection{Traditional Maternal Care During Delivery}

Rajbanshi by culture believes that pregnancy and delivery are special states during which a woman need care and support. All women said that their family members are supportive 
during pregnancy and delivery. Husbands loved more and helped for cooking food, wash clothes, bring nutritious foods from bazaar during pregnancy. In addition, they take care of newborn. Mother in law also extended hands in cleaning of the house, treating delivered mother by the body massage. Mother in law showed love and affection to both mother and the newborn. Neighbors also came to see and became a part birth ritual during and after delivery. Neighbors involved during and after delivery in the ritual of a naming of the baby and they also provided necessary help.

TBA traditionally manages home delivery. She conducts only normal deliveries. If labor gets prolonged, she refers to a hospital. TBA also suggests hospital delivery. Sometimes family member also calls health workers for home delivery along with TBA. If there is normal home delivery, they use a delivery kit with a sterile blade, thread, and cover plastic etc. in - home delivery. But today, most of the pregnant women prefer hospital delivery. There is a traditional treatment of hot massage with mustard oil mixed with ginger and onion given to mother right after home delivery. Boiled rice (jaulo) and ghee, carom (juwano), meat and other hot food will be given to a delivered mother. After delivery, mother in law cleans the house and took care of children. In some clusters a TBA gives bath the newborn with warm water, covers with new cloth and put on a nanglo. She shows the baby to neighbor and relatives on the second day that is a short cut method.

TBAs play an important role during delivery. A senior TBA who had huge experience of delivery practice in Rajbanshi community shared her experience as:

There is huge difference noticed in practices between present and past. During the past, there were traditional healers who used to 'jharphuk' and chanting mantras into water pot with holy basil (tulashi) leaf and give pregnant woman to drink and some water sprinkled on the body. Performing after traditional rituals healer lets family and TBA to start delivery procedure. At that time, we used to apply rubbing over the stomach of a pregnant woman for the quick delivery. Now we learned it was harmful practice. At the past, we did not have any knowledge about the need of an antenatal check up during pregnancy. So, maternal death was common during past days which are rare now in the community. TBA1

Home delivery by health workers is also common in the community. A health worker who attempted several home deliveries in Rajbanshi community shared the views:

First I cut my nails and wash hands with soap and water. I clean ground to make a delivery site. There will be clean blades, clothes ready. First I assess the general condition of mother and then check thoroughly per vagina. I check per vagina whether external os and internal os are fully dilated or not. If there is watery discharge present, I will try it for normal delivery. If both osare not fully dilated or blood discharge present, I will refer the mother to nearby hospital. HW3

\subsection{Traditional Maternal Care After Delivery}

A delivered mother called puwati. Naming of baby nwaran or pachhati or chhatiyar takes place on sixth day for male baby or on third day for female baby. On the day, they apply oil massage and wear a black thread to the baby. They keep leaves of jujube (bayar) and fish net near the door. They clean baby rubbing with a soft cloth during winter to prevent from the cold. They clean baby rubbing with a piece of cloth and warm water during summer. A local barber shaves the head of the baby and cut nails. The baby wears black threads over wrist and legs. The mother wears sindoor on her forehead. Father and mother of the baby also cut their nail on the day. They burn mustard oil pinaand guithaon a pot, and take it five rounds of the house, and put inside the house. They burn incense sticks with the belief that it will prevent baby from the common cold. They put five buckets of water over tube well to worship a deity of water jalkumarideota.

In this way, naming ritual nwaran takes place at home along with neighbors and relatives. People believe that family regain cleanliness after this ritual. Therefore, chhatiyar removes impurity and gives pureness in the house. A TBA cares the mother at least for one and half month at home. A TBA said about mother and child care:

After a delivery procedure, we give mother cooked watery rice (jaulo) and other nutritious hot food. In her diet we give bread (roti), dry - beaten rice, ginger, onion, potato pickle, pulses (musuro) but we do not give her normally cooked rice and green vegetables. We also give her soup and meat or fish. Mother breastfed her baby as soon after delivery. Mother put her baby on a bed (doli) for sleep. The delivered woman would not allow to walk and to work in the water to protect from cold. We give mother warm water and nutritious foods. We also rub (massage) the body of mother and baby with garlic mixed mustard oil for one and half months. TBA5

\subsection{Harmful Maternal Care Practice and Stigma}

\subsubsection{Preference of Boy Baby}

TBAs, traditional healers, and some mothers said that family becomes happy when boy child is born. If a girl child is born that time, family members become unhappy. Some blame the mother for having a girl child. Thus, son preference attitude was found in the Rajbanshi community. They said it is because of boy continues clan of the family because daughter goes to other's house and she takes away property also in the form of dowry or dahej from the house. A TBA said:

There is a difference in caring of mother and baby on the basis of the sex of the baby. Usually, mother and baby get good care when boy baby is born. I get more gifts when the birth of a boy. TBA3

\subsubsection{Vulnerable Group of Mothers}

In the Rajbanshi culture, a woman who has ever lost a baby or had stillbirth is called a pithiya and a mother who had ever an abortion is called a chhatka. Community people assume them unholy and presume the cause of diseases and illnesses to others. A woman who does not sit on the seat (pirca) presumed practicingtantra/mantra. Such woman is unfriendly and potential cause of the disease to others. A traditional healer said about precaution to take from such women:

When the pithya, chhatka, and tantra/mantra practicing women touch a baby it causes disease and illness. Therefore 


\section{children should keep away from them. TH4}

\subsection{Traditional Ritual of Child Care}

In Rajbanshi culture, the birth of the first baby should take place at natal home where they give rice pudding before a delivery. After the birth, the husband's family visits the wife's house with small gifts. Naming baby Chhattiyar also called as pachhati, or suddhabad, or nwaran that takes place on the sixth day for boy child and on the third day for a girl child. On the chhattiyara barber cuts mother's nails and shave baby's head to make ritually clean. On that, the Guru Gosai puts the newborn on a tray nanglo and shows to the sun - god. This is gratitude to the god. Guru Gosai worships clan deity and asks the permission to include the newborn as the member of the clan. The mother gets ritually clean after six days of chhattiyar.

Rice feeding ceremony celebrateson a day between five to nine months depending on the sex of the child. Maternal uncle makes rice pudding and feeds to the baby. The uncles bear the expenses incurred upon the celebration.

\subsection{Preventive Measure of Child}

They believe that tika of gazal paint on the forehead of a baby protects from evil eyes. It protects baby from a woman who practicestantra/mantra. Mothers are aware and take their children away from pithiya, chhatka and tantra/mantra practicing woman. They keep a domestic weapon knife (kachiya) under the bed of a child to protect from evil spirits.

\subsection{Harmful Child Care Practices}

The practice of shaving off newborn's head after delivery was found in some clusters in Jhapa Rajbanshi. A local traditional barber shaves neonate's head that do not have knowledge about sterilization of knife. A case of neonatal tetanus after shaving head recorded in Jhapa. A health worker reported that a child died from neonatal tetanus resulted after three - four days of shaving off the head. Now there is growing awareness of using new blades observed in many areas. Many clusters do not shave newborn head currently. But practice of using barber to cut umbilical cord during home delivery is still common. It may cause infection due to use of unsafe knife. On the other it can cause bleeding due to delaying of cutting the cord when barber becomes unavailable. At the moment, a TBA or health worker cuts off umbilical cord with a new blade is a change in practice.

\subsection{Cost of Treatment}

Mothers reported that cost for traditional care is affordable to them. Traditional healers did not have any fixed rate of their fees. Community people pay them according to the economic condition. Additionally mothers reported hospital treatment is expensive and they have to borrow money when they go to the hospital. Government of Nepal has managed free of charge in government hospitals during delivery. But its coverage is still low (less than 60\%) as per government report.

\subsection{Access of Cares}

Traditional healers are easily accessible. One of the major causes of using traditional care is their accessibility when people seek care. They have road and transportation reached almost all clusters. They use ambulance, motor, motorcycle, rickshaw, etc as means of transportation.

\section{Discussion}

Globally, there is diversity in the perception on disease and illnesses. Indian women considered tiredness, weakness and dizziness are part of a normal pregnancy and not symptoms for anemia and, thus, women do not seek treatment [23]. In a study by Dinç noted that $72 \%$ of the mothers believed in the evil eye in Turkey [24]. Baser et al. in a study noted some harmful practices during care of mother and child in Turkey [25]. The study recommended to join that findings knowledge in nursing curriculum and suggested to conduct more longitudinal studies on harmful practices.

In Nepal, Costello \& Anthony has pointed out that different studies are under taken on the traditional care of mother and child in different ethnics. Naming day of baby nwaran ranges from three to eleven days after birth in different ethnics. The ceremony for a daughter is earlier than for a son. For the ceremony, the house cleaned or plaster with cow dung and mud. Cow's urine sprinkled around the house for purification. Usually, a priest blesses the baby, gives a name and a chino. The name will not tell to others. A thread chanted with mantra may tie around the baby's waist and wrist: "if one does such things no - one will be jealous of the baby" [26]. Exposure to sunlight considered important for such sunlight believed to bring a bright future for the infant [27]. Bennett also described nwaran ceremony, when the baby is shown to the sun"' [28]. With this ceremony, the duration of impurity or sutak that started immediately after the birth will end. The family including the mother and the baby regarded purified from this formal special event onwards. The mother allowed moving in the house and in other places.

In Rajbanshi community, traditional perspective on causes of Diseases are: (1) Deity, (2) Witchcraft or woman who uses Tantra, Mantra, (3) Evil spirits or dead children, (4) Pithiya/Chhatka: touching or watching by women who had lost babies or had still births or abortions and (5) dirt or poor sanitation of houses. Traditional healers find out the cause of disease or illness after looking jokhana in a patient. After jokhana, they prescribe treatment correspondingly. Rajbanshi traditional treatment comprises of the treatment package. They worship house deity or Ghardeota and do jharphuk by chanting mantras and sacrifice of animals or offer goods to deity. Sometimes they sacrifice animal or goods during the course of treatment. Traditional healers had a package for treatment by doing jharphuk, using jadibuti, buti, and promising ferani or bhakal. In jharphuk or phukphak, they chant mantra 5 or 6 times. They use single or multiple methods according to the disease and severity. If would not recovered after $1-2$ days be referred to a doctor. 
Culturally there are a number of good practices found in caring of a pregnant and delivered woman who has a child. Mothers are encouraged to breast feeding to the child and give nutritious food to lactating woman. Care and support by husband, mother in law and other family make delivery safely. Many newborn care practices are typical and neonatal friendly. On the other side son, preference culture and practice has guided to have more childbirth until a son birth. So, multiple pregnancies may lead maternal morbidity and mortality due to possible complications. Caring mother and child are good when boy born. Such kind of gender discrimination creates an environment for maternal and child mortality.

Now public health infrastructure and private health facility are strengthening in the Rajbanshi community. Harmful practices are now discouraged. Newborn shaving of head now discouraged. Cutting of umbilical cord by a barber was not compulsory if not available. Now health workers or trained TBA can cut the umbilical cord of a newborn during delivery. It was possible due to availability of health workers, health facility, and transportation. The number of neonatal or maternal deaths due to bleeding caused by delay in cutting the umbilical cord is now rare which was common before. In the modern medical system and social realities, issues of socioeconomic class, gender, ethnicity, and occupation often play role in the context. Epidemiological distribution of disease is not fair from one social group to another. Generally, very poor, labor, rural and traditional practicing people have higher rates of illness and mortality than general in Rajbanshi community.

\section{Limitation of the Study}

Rajbanshi by literally includes various types of communities. They have largely cultural variation from place to place in Nepal. The scope of study includes communities living in Morang, Jhapa and Sunsari districts who are Hindu by culture.

\section{Conclusion}

Rajbanshi community in Nepal has native cultural practice in caring mother and child during pregnancy, delivery and postnatal period. During which they follow the ritual and use traditional healers Guru Gosai, Gosai, Ojha and Dhami. Guru Gosais are essential in birth, marriage and death rituals also. Hence traditional practices are deeply rooted. In traditional health care they do preventive and curative care. They believe that deities, witchcraft, evil spirit, pithiya/chhatka and poor sanitation are causes of diseases. They diagnose a disease by looking jokhana. They treat patients by jharphuk, jadibuti, buti and ferani. They experience maternal and child mortality became low due to good access of health care services provided by public and private sectors.

The stigma on pithiya and chhatka women is serious. The cutting off an umbilical cord by a barber and shaving off the head of the newborn are harmful practices although it is decreasing. Reestablishment of the pithiya and chhatka women in the community by awareness is urgent. Training is necessary for barbers on sterile techniques to cut an umbilical cord and to shave off a newborn's head.

\section{Definitions of Key Words}

Aalibarne: Prevention for safe delivery

Bhakal: Promise something with deity

Buti: Traditional medicine to wear

Chhatiyar: Sixth day after delivery or naming of baby

Chhatka: woman who had abortion

Chino: Gift

Deota: Deity

Dhami: Traditional healer

Dhaiaama: Traditional birth attendant

FCHV: Female Community Health Volunteer

Ferani: Promise something with deity

Gazal: A black paint made from smoke

Ghardeota: House god

Gosai: Traditional healer

Grahabigriyo: Misfortune

Guitha: Domestic firewood made from cow dung.

Guru Gosai: Traditional healer

Jadibuti: Traditional medicine to take

Jharphuk: Traditional treatment

Jokhana: Traditional diagnostic method

Mantra: A word or formula sung as an incantation

Nanglo: Domestic tray made from bamboo

Nwaran: Naming of baby ceromony

Ojha: Traditional healer

Pachhati: Naming of baby.

Phukphak: Traditional treatment

Pina: Mustard seed residue apart from oil

Pithiya: woman who lost baby or stillbirth

Sudeni: Traditional birth attendant

Puwati: Delivered woman

Tantra: A Hindu or Buddhist mystical or magical text

Sindoor: Vermillion

TBA: Traditional birth attendant

Tika: A mark on forehead

Tulasi: Basil plant

\section{Authors' Contributions}

Nawa Raj Subbaas a researcher conceptualized and conducted the study under the guidance of Prof. Shishir Subba and Prof. Shanta Niraula. Researcher analyzed the data, interpreted them and wrote the article based on the findings. The article has incorporated feedback given by the research guides.

\section{Authors' Information}

Nawa Raj Subba has Doctor of Philosophy in Health Psychology from Tribhuvan University. He worked more than three decades in the field of public health in Nepal. He is now independent researcher and consultant in different institutions and universities. 


\section{Acknowledgements}

I am grateful to Prof. Shishir Subba and Prof. Shanta Niraulafor the invaluable guidance in the study. I am also grateful to Prof. Som Khatiwada for the support in the study. I thank Jyotish Rajbanshi, Muluk Chand Rajbanshi, and Kamal Singh Rajbanshi for arranging interviews and facilitating meetings during data collection.

\section{References}

[1] Dixit. The Quest for Health. Kathmandu, Educational Enterprises (P) Ltd. 2009.

[2] Hitchcock, J. Spirit Possession in the Nepal Himalayas. Warmister: Aris and Philips. 1976.

[3] Hawran, D. Vergleichende Untersuchungenuber Krankheitsauffassungen und Krankheitsverhlaten in zweinepalesischen Dofern. Freiburg: Unpublished Dissertation, cited from Boker, H. (1992) Concepts of Mental Illness: An Ethnographic Study, Contributions to Nepalese Studies, 1981. Vol. 19, No. 1.

[4] Shrestha et. al. A Social and Psychiatric Study of Mental Illness in Nepal. Internatrional Year of Disabled Persons Committee. Handicapped Services Co - ordination Committee. Kathmandu/Nepal: United National Children Fund. 1983.

[5] Stone, L. Concepts of Illness and Curing in Central Nepali Village. CNAS/TU Contributions to Nepalese Studies, 3 (Special Issue): 1976 pp55 - 80.

[6] NMMMS. Nepal Maternal Mortality and Morbidity Study; Summary of Preliminary Findings, Kathmandu, Ministry of Health and Population, Family Health Division.2008/09.

[7] NDHS. National Demographic Health Survey of Nepal. Ministry of Health and Population. 2011.

[8] MoHP. National Health Policy 2071. Government of Nepal, Kathmandu, Ministry of health and Population. 2014.

[9] Lomov, B. F., Budilova E. A., Koltsova V. A., Medvedev A. M. Indigenous Psychology: Research and experience in cultural context. New Delhi India, SAGE publications. 1993.

[10] Kim, U., Berry J. W. Indigenous Psychologies: Research and Experience in Cultural Context, New Delhi. SAGE Publication, 1993.

[11] Moghaddam, F. M. Traditional and Modern Psychologies in competing cultural Systems: Lessons from Iran 1978 - 1981, Indigenous Psychologies: Research and Experience in Cultural Context, New Delhi. SAGE Publication, 1986 pp118 - 131.

[12] White, G. M. Cultural Explanation of Illness and Adjustment: A Comparative Study of American and Hongkong Chinese Students. Washington D. C.: Vortraganla Blich der 79. Konferenz AmerikanischenAnthroplogischenGesellschaft.1980.

[13] Berger, P. L. \& Luckmann, T. The social construction of reality. Garden City, NY: Anchor. Berger, 1966.
[14] Bobbie P., Addiss, D., Bartholomew, K., Meijer1, C., Pou, V., Van, B. Health - seeking behaviors and self - care practices of Dominican women with lymphoedema of the leg: implications for lymphoedema management programs. 2006.

[15] MDAA. Some Vietnamese Cultural Practices and their Implications for Service Providers. www.mdaa.org.au. Retrieved Nov 5, 2014.

[16] Kanchense, J. Urologic and Gynecologic Health problems among Zimbabwean women: Harmful cultural practices. Urologic Nursing. 2007; 27 (5): pp373 - 389.

[17] Ahmed et al. Changing Health Seeking Behavior in Matlab: Do Development Interventions Matter? Health Policy Plan 2003; Oxford University Press.2003, vol: 18; pp306-315.

[18] Iyengar, et al. Pregnancy - related deaths in rural Rajasthan, India: exploring causes, context, and care - seeking through verbal autopsy. Journal of Health, Population and Nutrition. 2009 Apr; 27 (2): pp293 - 302.

[19] Singh, et al. Husbands' reproductive health knowledge, attitudes, and behavior in Uttar Pradesh, India, Chapel Hill 27516 - 3997, USA. Carolina Population Center, University of North Carolina.1998.

[20] Lustain, H. Levels of Medicine in a Central Nepali Village, CNAS Journals, Vol.3. Tribhuvan University Kirtipir Kathmandu Nepal.1976.

[21] Stone, L. Concepts of Illness and Curing in Central Nepali Village. CNAS/TU Contributions to Nepalese Studies, 3 (Special Issue): 1976, pp55 - 80.

[22] Alasuutari P. Researching Culture: Qualitative method and Culture Studies. New Delhi, India. Sage Publication, 1995.

[23] Bentley, et al. Perceptions of anemia and health seeking behavior among women in four Indian states (Technical Working Paper \#9) 1998 Mother Care, John Snow Inc.1998.

[24] Dinç, S. To determine the traditional practices which mothers, having 0 - 1 years old children, registered to health center no 4 in Şanliurfa center. Society for Research and Development in Nursing, 2005, 1 (2), 53 - 63.

[25] Baser, A., Topcu, S., Coskun, A., Erdem, R., Gelisken, R., Ozer, D., Traditional child care practices among mothers with infantsless than 1 year old. Deuhyo Ed. 2010, 3 (3), 137 - 145.

[26] Costello, L. and Anthony, M. (2000). A qualitative description of perinatal care practices in Makwanpur District, Nepal, Contributions to Nepalese Studies, CNAS Journal.2000, vol 29: pp143 - 158 .

[27] Manandhar, M. Obstetric health perspectives of Magar and Tharu communities: a social research report to inform the Nepal Safer Motherhood Project's IEC strategy. Options; Department for International Development.2000.

[28] Bennett, L. Sitting in a cave: an analysis of ritual seclusion at menarche among Bramhin and chhetris in Nepal." Contributions to Nepalese Studies. 1978, 6: 32 - 45. 